\title{
EFEKTIFITAS PROSEDUR KEPABEANAN TERKAIT DENGAN DWELLING TIME UNTUK IMPORTASI DI KANTOR PELAYANAN UTAMA BEA DAN CUKAI TIPE C SOEKARNO HATTA TAHUN 2017
}

\author{
Tony Triyulianto, Pebriana Arimbhi ${ }^{1}$, Emanuel Ageng Pratama Labupili \\ Email: pebriana.arimbhi14@gmail.com ${ }^{1}$ \\ Institut IImu Sosial dan Manajemen STIAMI
}

\section{ARTICLE INFO}

Keywords:

Effectiveness,

Customs Procedures,

Dwelling Time

\section{ABSTRACT}

This research is intended to discuss the effectiveness of customs procedures related with dwelling time for importation in the Main Service Office of Customs and Excise Type C Soekarno Hatta in 2017. The main problem in this research is how the level of effectiveness of customs procedures and its relation with dwelling time for importation process in KPUBC Type C Soekarno Hatta. With ineffective implementation of customs procedures in the process of imported goods resulted in high dwelling time figures. With the existence of high dwelling time will certainly inhibit the smooth flow of importation process and the release of imported goods. This research is a qualitative descriptive research with data collection techniques in the form of interviews and secondary data. The results of interviews and data are then processed and analyzed to determine the effectiveness of customs procedures related to dwelling time for the importation in KPUBC Type C Soekarno Hatta in 2017. The results of this research, the authors conclude that KPUBC Type C Soekarno Hatta in 2017 seen from the aspect of the plan or program and the rules and regulations included in the category effective, whereas from the duties or functions and objectives or ideal conditions included in the category less effective. Therefore, for the future KPUBC Type C Soekarno Hatta can improve the effectiveness of customs procedures by minimizing the constraining entities that occur by using appropriate entrepreneurs. The author also advises KPUBC Type C Soekarno Hatta to provide performance guidance training to be more effective, to customs service users to learn all the rules and latest information on customs procedures and for DJBC itself is expected to take an active role in it.

\section{INTRODUCTION}

Penerimaan pajak merupakan sumber pembiayaan negara yang dominan baik untuk belanja rutin maupun pembangunan. Bagi Indonesia penerimaan pajak sangat besar peranannya untuk mengamankan anggaran negara dalam Anggaran Pendapatan dan Belanja Negara (APBN) setiap tahun, yang digunakan sebagai sumber dana bagi pemerintah dalam melaksanakan pembangunan.

Perkembangan pembagian penerimaan negara pada APBN dalam empat tahun terakhir dapat dilihat di tabel I.1 berikut: 
Tabel I.1 Penerimaan negara pada APBN (dalam triliun rupiah)

\begin{tabular}{|l|c|c|c|c|}
\hline Sumber penerimaan & 2014 & 2015 & 2016 & 2017 \\
\hline Penerimaan & 1246,1 & 1489,3 & 1539,2 & 1498,9 \\
& $(76,2 \%)$ & $(84,5 \%)$ & $(86,1 \%)$ & $(85,6 \%)$ \\
\hline Perpajakan & & & & \\
Bukan Pajak (PNBP) & $(23,7 \%)$ & $(15,3 \%)$ & $(13,7 \%)$ & $(14,3 \%)$ \\
& & & & 250 \\
\hline Hibah & 2,3 & 3,3 & 2,0 & 1,4 \\
& $(0,1 \%)$ & $(0,2 \%)$ & $(0,2 \%)$ & $(0,1 \%)$ \\
\hline Total & 1635,4 & 1761,6 & 1786,2 & 1750,3 \\
\hline & $(100 \%)$ & $(100 \%)$ & $(100 \%)$ & $(100 \%)$ \\
\hline
\end{tabular}

Sumber : situs www.kemenkeu.co.id

Berdasarkan tabel I.1 di atas, dapat dilihat bahwa penerimaan perpajakan masih menjadi penyumbang terbesar bagi pendapatan negara pada Anggaran Pendapatan dan Belanja Negara (APBN). Pada 4 tahun terakhir, pendapatan negara berasal dari penerimaan perpajakan selalu di atas $75 \%$ sehingga membuat sektor perpajakan menjadi obyek yang sangat vital bagi negara. Di dalam APBN, penerimaan perpajakan diklasifikasikan ke dalam 2 (dua) sektor yaitu penerimaan pajak dalam negeri dan penerimaan pajak perdagangan internasional.

Salah satu pos penerimaan perpajakan khususnya yang berasal dari sektor pajak perdagangan internasional adalah Bea Masuk. Menurut Undang-Undang nomor 17 tahun 2006 perubahan dari undangundang nomor 10 tahun 1995 tentang Kepabeanan, bea masuk didefinisikan sebagai "Pungutan negara berdasarkan undang-undang ini yang dikenakan terhadap barang yang diimpor". Pelaksanaan pemungutan bea masuk dibebankan kepada Direktorat Jenderal Bea dan Cukai yang merupakan salah satu unit setingkat Eselon I dibawah Kementerian Keuangan. Sebagai penghimpun penerimaan negara, Direktorat Jenderal Bea dan Cukai dituntut untuk dapat memaksimalkan penerimaan bea masuk tiap tahunnya. Hal ini sesuai dengan tugas dan

fungsi dari DJBC yaitu sebagai Trade Facilitator (memberi fasilitas perdagangan, diantaranya melaksanakan tugas titipan dari instansi lain), Industrial Assistance (Melindungi industri dalam negeri dari persaingan tidak sehat dengan industri sejenis dari luar negeri), Community Protector (Melindungi masyarakat dari masuknya barang-barang berbahaya) serta sebagai Revenue Collector (memungut pajak atas barang impor, barang ekspor serta cukai secara maksimal).

Kantor Pelayanan Utama Bea dan Cukai Tipe C Soekarno Hatta merupakan salah satu kantor pelayanan bea dan cukai yang berada dibawah Direktorat Jenderal Bea dan Cukai. Sebagian besar kegiatan importasi melalui udara di Indonesia dilakukan melalui bandara internasional Soekarno Hatta. Oleh karena hal tersebut, KPU Bea dan Cukai Tipe C Soekarno Hatta sebagai salah satu kantor pelayanan di DJBC dalam tugas dan fungsinya sebagai revenue collector setiap tahunnya diberikan beban target penerimaan yang cukup besar dalam bidang bea masuk dan bea keluar, cukai serta PDRI lainnya. 
Khusus di sektor bea masuk, target penerimaan bea masuk KPU Bea dan Cukai Tipe C Soekarno Hatta untuk tahun 2017 sebesar 4,04 triliun rupiah. Realisasinya sekitar 4,17 triliun rupiah sehingga tahun 2017 KPU Bea dan Cukai Tipe C Soekarno Hatta mencapai dan bahkan melebihi target dengan total 103,33\% Jika tren realisasi penerimaan bea masuk seperti itu terus dipertahankan tentu akan berdampak positif ke penerimaan negara.

Di sisi lain, selain melakukan tugas dan fungsi sebagai revenue collector, KPU Bea dan Cukai Tipe C Soekarno Hatta juga melakukan tugas dan fungsi sebagai Trade Facilitator dan Community Protector. Dalam pelaksanaan tugasnya sebagai Trade Facilitator, KPU Bea dan Cukai Tipe C Soekarno Hatta melakukan tugas berupa penegakan peraturan yang dititipkan dari instansi lain yang berkepentingan terhadap importasi komoditi tertentu, baik berupa aturan mengenai pembatasan maupun pelarangan impor. Tata cara penyelesaian impor saat ini berlaku prinsip self assesment dimana importir secara mandiri memberitahukan dokumen ke kantor pabean. Dalam prosedur kepabeanan penyelesaian barang impor, KPU Bea dan Cukai Tipe C Soekarno Hatta harus memastikan kebenaran pemberitahuan barang atas barang yang diimpor melalui penelitian dokumen dan pemeriksaan fisik barang. Namun di dalam kepabeanan, pemeriksaan fisik barang hanya dilakukan terhadap importasi yang mendapatkan jalur merah, sedangkan terhadap importasi yang mendapatkan jalur hijau, kuning dan jalur prioritas dilakukan penelitian dokumen tanpa pemeriksaan fisik barang. Berikut data yang menggambarkan jumlah dokumen Pemberitahuan Impor Barang (PIB) dan penjaluran importasi pada KPU BC Tipe C Soekarno Hatta pada tahun 2017 :

Tabel I.2 Jumlah Dokumen PIB dan Penjaluran Importasi Tahun 2017

\begin{tabular}{|c|c|c|}
\hline Jalur & $\begin{array}{c}\text { Jumlah Dokumen } \\
\text { PIB }\end{array}$ & Persentase (\%) \\
\hline Merah & 23.659 & 7.03 \\
\hline Kuning & 46.842 & 13.92 \\
\hline Hijau & 206.233 & 61.27 \\
\hline Prioritas & 59.837 & 17.78 \\
\hline TOTAL & 336.571 & 100 \\
\hline
\end{tabular}

Sumber : KPUBC Tipe C Soekarno Hatta

Dari data diatas, importasi yang mendapatkan jalur merah hanya sebesar $7.03 \%$ atau sekitar 23.659 PIB dari total 336.571 PIB. KPU Bea dan Cukai Tipe C Soekarno Hatta tidak mungkin melakukan pemeriksaan fisik terhadap semua importasi dikarenakan volume importasi yang cukup tinggi. Hal ini terkait juga dengan Dwelling Time yaitu waktu rata-rata yang dibutuhkan oleh satu kontainer atau paket kiriman mulai dari bongkar sampai dengan keluar pelabuhan/bandara (gate-out). Semakin tinggi persentase pemeriksaan fisik maka dapat dipastikan semakin tinggi pula angka Dwelling Time yang dibutuhkan.

Dalam kaitannya dengan penerapan Dwelling Time, Bea Cukai memiliki peran penting dalam hal prosedural dan pengawasan. Bea Cukai dalam melaksanakan tuganya tentu menghadapi berbagai kendala. Dibutuhkan strategi yang tepat dalam mengatasi kendala-kendala yang dihadapi agar Dwelling Time dapat dikurangi. Percepatan Dwelling Time berkorelasi dengan penurunan biaya logistik dalam perdagangan internasional. Oleh karena itu, usaha yang maksimal dari seluruh pihak diharapkan dapat mempercepat Dwelling Time di Indonesia.

Permasalahan Dwelling Time di Indonesia mulai banyak dibicarakan setelah presiden Indonesia, Joko Widodo mengungkapkan ketidakpuasannya terhadap tingkat Dwelling Time di Indonesia. Presiden Jokowi juga menyoroti beberapa pelabuhan lain seperti pelabuhan Tanjung Priok, Makassar, dan Tanjung Perak, walaupun tingkat Dwelling Time di beberapa pelabuhan tersebut sudah lebih cepat dibandingkan dengan pelabuhan Belawan, Presiden Jokowi meminta agar pengelola semakin mempercepatnya lagi (Kompas.com. 2017).

Bandara Internasional Soekarno Hatta tentu tak luput dari masalah Dwelling Time. Jumlah importasi barang kargo yang melalui bandara internasional Soekarno Hatta menunjukkan rasio yang tinggi. KPU Bea

Tony Triyulianto, et.al (Efektifitas Prosedur Kepabeanan Terkait Dengan Dwelling Time...) 
dan Cukai Tipe C Soekarno Hatta sebagai kantor pelayanan yang bertanggung jawab terhadap lalu lintas barang ekspor dan impor melalui udara harus mampu bekerja dengan semaksimal mungkin terutama dalam penerapan Dwelling Time. Semua pihak diharapkan dapat saling bekerjasama bengan baik dan ikut berkontribusi secara maksimal agar permasalahan terkait Dwelling Time dapat diatasi.

Tabel I.2 menunjukkan jumlah dokumen PIB dan penjaluran importasi melalui gudang impor kargo bandara internasional Soekarno Hatta pada tahun 2017. Arus penyelesaian importasi melalui prosedur kepabeanan di gudang impor terbagi menjadi tiga tahapan yaitu pre clearance, customs clearance, dan post clearance. Tahapan-tahapan tersebut tentu akan memunculkan Dwelling Time dalam setiap importasi barang kargo yang masuk.

Jumlah dokumen Pemberitahuan Impor Barang (PIB) sekitar 336.571 dokumen yang terdiri dari PIB jalur hijau, jalur kuning, jalur merah dan jalur prioritas tentu akan memunculkan rata-rata Dwelling Time yang berbeda-beda di tiap-tiap tahapnya. Berikut dilampirkan data Dwelling Time masing-masing jalur yang ada di KPU Bea dan Cukai Tipe C Soekarno Hatta selama tahun 2017.

Tabel I.3 Dwelling Time importasi (dalam hari)

KPU Bea dan Cukai Tipe C Soekarno Hatta (tahun 2017)

\begin{tabular}{|c|c|c|c|c|c|c|}
\hline Jalur & Bulan & $\begin{array}{c}\text { Pre } \\
\text { Clearance }\end{array}$ & $\begin{array}{l}\text { Customs } \\
\text { Clearance }\end{array}$ & $\begin{array}{c}\text { Post } \\
\text { Clearance }\end{array}$ & $\begin{array}{c}\text { Dwelling } \\
\text { Time }\end{array}$ & $\begin{array}{c}\text { Jumlah } \\
\text { PIB }\end{array}$ \\
\hline \multirow[t]{12}{*}{ Prioritas } & Januari & 3.75 & 0.00042 & 0.64 & 4.38 & 2905 \\
\hline & Februari & 2.93 & 0.001382 & 0.66 & 3.59 & 2695 \\
\hline & Maret & 3.43 & 0.00053 & 0.72 & 4.15 & 3223 \\
\hline & April & 4.29 & 0.00160 & 0.98 & 5.28 & 3137 \\
\hline & Mei & 4.87 & 0.00086 & 1.17 & 6.04 & 5080 \\
\hline & Juni & 4.93 & 0.0002980 & 1.34 & 6.27 & 4071 \\
\hline & Juli & 5.67 & 0.0003264 & 1.09 & 6.76 & 5455 \\
\hline & Agustus & 4.12 & 0.0003352 & 1.11 & 5.23 & 5954 \\
\hline & September & 4.39 & 0.0004153 & 0.95 & 5.34 & 5709 \\
\hline & Oktober & 3.93 & 0.0005749 & 0.80 & 4.74 & 6226 \\
\hline & November & 4.41 & 0.0005556 & 0.78 & 5.19 & 7035 \\
\hline & Desember & 4.76 & 0.0004709 & 0.92 & 5.68 & 5443 \\
\hline \multirow[t]{8}{*}{ Hijau } & Januari & 5.17 & 0.00086 & 0.55 & 4.38 & 13782 \\
\hline & Februari & 4.6 & 0.001436 & 0.58 & 5.73 & 13521 \\
\hline & Maret & 4.78 & 0.00074 & 0.61 & 5.39 & 16352 \\
\hline & April & 5.39 & 0.00309 & 0.85 & 6.24 & 14327 \\
\hline & Mei & 6.81 & 0.00086 & 0.96 & 7.77 & 17650 \\
\hline & Juni & 8.90 & 0.0002977 & 1.02 & 9.92 & 15813 \\
\hline & Juli & 9.01 & 0.0003266 & 1.31 & 10.32 & 20531 \\
\hline & Agustus & 7.17 & 0.0003102 & 1.33 & 8.51 & 18845 \\
\hline
\end{tabular}

Tony Triyulianto, et.al (Efektifitas Prosedur Kepabeanan Terkait Dengan Dwelling Time...) 
Volume 1, Nomor 1, September 2019, pp. 22-38

\begin{tabular}{|c|c|c|c|c|c|c|}
\hline & September & 6.96 & 0.0007541 & 0.92 & 7.88 & 15468 \\
\hline & Oktober & 6.34 & 0.0005229 & 0.66 & 7.01 & 18392 \\
\hline & November & 6.40 & 0.0005700 & 0.62 & 7.02 & 19273 \\
\hline & Desember & 6.48 & 0.0005054 & 0.65 & 7.13 & 16518 \\
\hline \multirow[t]{12}{*}{ Kuning } & Januari & 5.29 & 2.54 & 0.58 & 4.38 & 1165 \\
\hline & Februari & 4.38 & 2.47 & 0.62 & 8.41 & 1112 \\
\hline & Maret & 4.68 & 2.42 & 0.61 & 7.72 & 1460 \\
\hline & April & 5.29 & 2.63 & 0.88 & 8.75 & 1282 \\
\hline & Mei & 6.88 & 2.68 & 0.92 & 10.48 & 1661 \\
\hline & Juni & 10.55 & 2.50 & 1.01 & 14.05 & 1801 \\
\hline & Juli & 9.86 & 2.86 & 1.37 & 14.09 & 1797 \\
\hline & Agustus & 6.98 & 2.97 & 1.12 & 11.07 & 4567 \\
\hline & September & 6.66 & 3.36 & 0.92 & 10.94 & 6598 \\
\hline & Oktober & 6.34 & 3.06 & 0.73 & 10.13 & 7227 \\
\hline & November & 6.54 & 2.67 & 0.68 & 9.89 & 8283 \\
\hline & Desember & 6.97 & 2.95 & 0.75 & 10.67 & 7920 \\
\hline \multirow[t]{12}{*}{ Merah } & Januari & 7.93 & 3.82 & 0.55 & 12.31 & 821 \\
\hline & Februari & 8.29 & 3.86 & 0.52 & 12.67 & 827 \\
\hline & Maret & 6.22 & 4.00 & 0.63 & 10.86 & 1120 \\
\hline & April & 6.59 & 4.37 & 0.77 & 11.73 & 1009 \\
\hline & Mei & 7.46 & 5.30 & 0.79 & 13.55 & 1314 \\
\hline & Juni & 10.08 & 6.15 & 0.97 & 17.20 & 1479 \\
\hline & Juli & 12.33 & 10.85 & 1.38 & 24.57 & 1590 \\
\hline & Agustus & 10.09 & 7.96 & 1.28 & 19.32 & 2287 \\
\hline & September & 9.33 & 7.94 & 0.94 & 18.21 & 2253 \\
\hline & Oktober & 9.21 & 7.77 & 0.68 & 17.65 & 2951 \\
\hline & November & 8.96 & 6.06 & 0.64 & 15.66 & 3446 \\
\hline & Desember & 8.60 & 7.16 & 0.73 & 16.49 & 3113 \\
\hline
\end{tabular}

Sumber : KPUBC Tipe C Soekarno Hatta

Dwelling Time di tabel I.3 tersebut merupakan penjumlahan dari tahap Pre Clearance, Customs Clearance, dan Post Clearance. Dalam upaya memperkecil angka dari Dwelling Time, Bea dan Cukai tentu

Tony Triyulianto, et.al (Efektifitas Prosedur Kepabeanan Terkait Dengan Dwelling Time...) 
mempunyai peranan yang cukup signifikan di tahapan Customs Clearance. Prosedur kepabeanan diterapkan dalam tahapan tersebut dari tahapan penjaluran, pemeriksaan dokumen Pemberitahuan Impor Barang (PIB) maupun pemeriksaan fisik sampai diterbitkannya Surat Persetujuan Pengeluaran Barang ( SPPB ) oleh Bea dan Cukai.

Fenomena yang terjadi dapat di lihat dari data tersebut di atas, menunjukkan bahwa waktu terkait dengan proses customs clearance (dwelling time) di bidang pelayanan dan fasilitas pabean dan cukai pada kegiatan impor untuk gudang impor di Bandara Soekarno Hatta masih tinggi yaitu lebih dari 2 hari khususnya untuk jalur kuning dan jalur merah. Hal ini dapat mengakibatkan ketidakefektifan dalam pelaksanaan prosedur kepabeanan terutama untuk mencapai kelancaran arus barang yang merupakan salah satu tugas dari DJBC.

Dalam hal prosedur kepabeanan, Importir / Pengguna Pengurusan Jasa Kepabeanan (PPJK) menerapkan sistem self assesment pada dokumen Pemberitahuan Impor Barang (PIB), lalu ada sistem penetapan jalur yang ditetapkan oleh DJBC. Dari proses kepabeanan tersebut dapat terjadi adanya penerbitan Nota Hasil Intelijen (NHI) terhadap importasi yang mendapatkan jalur prioritas, hijau, dan kuning yang masih banyak terjadi karena adanya pelanggaran terutama terkait dengan pembayaran bea masuk yang tidak sesuai serta pemenuhan perijinan impor dari kementerian terkait. Terhadap barang NHI tersebut juga harus dilakukan pemeriksaan fisik. Selain itu, importasi jalur merah di KPU Bea dan Cukai Tipe C Soekarno Hatta yang memerlukan pemeriksaan fisik barang di gudang impor semakin meningkat di tiap bulannya sehingga akan menambah penuh gudang impor. Dalam hal penyelesaian importasi barang, Kantor Pelayanan Utama Bea dan Cukai Tipe C Soekarno Hatta sebagai kantor yang beralamat di area bandara tentunya memiliki target dwelling time tersendiri. Dalam prakteknya, Direktorat Jenderal Bea dan Cukai membebani KPU Bea dan Cukai Tipe C Soekarno target dwelling time penyelesaian setiap jalurnya yaitu hanya 1 hari. Itu tercermin di kontrak kinerja Kepala KPU Bea dan Cukai Tipe C Soekarno Hatta. Berdasarkan tabel I.3, prosedur kepabeanan (customs clearance) yang dilakukan oleh bea cukai Soekarno Hatta terhadap 4 jalur yang ada, 2 jalur sudah memenuhi target dwelling time yaitu jalur prioritas dan jalur hijau sedangkan 2 jalur lainnya yaitu merah dan kuning masih melebihi target dwelling time 1 hari tersebut.

Oleh karena hal-hal tersebut, ada indikasi bahwa prosedur kepabeanan yang dilakukan oleh KPU Bea Cukai Tipe C Soekarno Hatta masih kurang efektif yang tercermin dari angka dwelling time yang melebihi 1 hari penyelesaiannya. Efektifitas dari prosedur kepabeanan untuk memperlancar arus barang impor yang berada di gudang impor terkait dengan target Dwelling Time 1 hari di setiap jalurnya akan menjadi tolak ukur yang memegang peran signifikan. Selain itu, entitas yang berpengaruh dalam pelaksanaan prosedur kepabeanan tersebut baik itu entitas penghambat maupun pendorong juga akan menjadi acuan yang berpengaruh terhadap dwelling time yang ada di KPU Bea dan Cukai Tipe C Soekarno Hatta.

Tulisan ini mencoba untuk melihat prosedur kepabeanan terkait dengan $d$ welling time untuk importasi di Kantor Pelayanan Utama Bea dan Cukai Tipe C Soekarno Hatta.

\section{LITERATUR REVIEW}

Diskusi tentang prosedur kepabeanan terkait dengan dwelling time untuk importasi di Kantor Pelayanan Utama Bea dan Cukai Tipe C Soekarno Hatta. Wiradi (Lestari,2013: 1), menyatakan bahwa, Analisis adalah aktivitas yang memuat sejumlah kegiatan seperti mengurai, membedakan, memilah sesuatu untuk digolongkan dan dikelompokkan kembali menurut kriteria tertentu kemudian dicari kaitannya dan ditaksir maknanya.

Komaruddin (Lestari, 2013: 1), menyatakan bahwa, Analisis adalah kegiatan berfikir untuk menguraikan suatu keseluruhan menjadi komponen sehingga dapat mengenal tanda-tanda komponen, hubungannya satu sama lain dan fungsi masing-masing dalam satu keseluruhan yang terpadu. Sedangkan Darminto dan Julianty (Lestari, 2013: 1) mengemukakan bahwa, Analisis merupakan penguraian suatu pokok atas berbagai bagiannya dan penelaahan bagian itu sendiri, serta hubungan antar bagian untuk memperoleh pengertian yang tepat dan pemahaman arti keseluruhan. Adapun, menurut Gorys Keraf (2008: 5), analisis merupakan sebuah proses untuk memecahkan sesuatu ke dalam bagian-bagian yang saling berkaitan satu sama lainnya.

Menurut Zaki Baridwan (2009 : 30), Prosedur adalah suatu urutan-urutan pekerjaan klerikal (clerical), biasanya melibatkan beberapa orang dalam satu bagian atau lebih, untuk menjamin perlakuan yang seragam

Tony Triyulianto, et.al (Efektifitas Prosedur Kepabeanan Terkait Dengan Dwelling Time...) 
terhadap transaksi-transaksi perusahaan yang terjadi”. Sedangkan menurut Crisyanti (2011 :143), Prosedur adalah tata kerja yaitu rangkaian tindakan, langkah atau perbuatan yang harus dilakukan oleh seseorang dan merupakan cara yang tetap untuk dapat mencapai tahap tertentu dalam hubungan mencapai tujuan Akhir. Adapun menurut Mulyadi (2013:5), Prosedur adalah Suatu urutan kegiatan klerikal, biasanya melibatkan beberapa orang dalam satu departemen atau lebih, yang dibuat untuk menjamin penanganan secara seragam transaksi perusahaan yang terjadi berulang-ulang.

Definisi Prosedur Kepabeanan menurut UU no 17 tahun 2006 tentang kepabeanan dan modu UndangUndang Pabean oleh Drs Ahmad Dimyati, prosedur kepabeanan merupakan proses penyelesaian dan pengurusan berbagai dokumen administrasi (dokumen impor/ekspor) dan terhadap dokumen tersebut telah diperiksa serta terhadap beberapa barang impor/ekspor dilakukan pemeriksaan fisik sampai dengan tahap diterbitkan Surat Persetujuan Pengeluaran Barang (SPPB) oleh Bea dan Cukai.

Pemeriksaan fisik terhadap barang yang dilaksanakan oleh Pejabat Bea dan Cukai bersifat selektif dalam arti bahwa pemeriksaan fisik dilaksanakan setelah membuat suatu analisis. Barang yang diimpor dikategorikan ke dalam tiga tingkatan yaitu tinggi (high-risk), menengah/sedang (medium-risk), dan rendah (low risk), tergantung dari hasil analisis yang dilakukan petugas.

Tindakan penetapan jalur merupakan bagian tidak terpisahkan dari kegiatan penelitian administrasi. Penetapan jalur pengeluaran barang impor didasarkan atas profil importir, yang dibuat oleh bagian pengawasan dan profil komoditi yang disusun berdasarkan perkembangan importasi jenis-jenis barang yang banyak dilakukan pelanggaran. Profil importir dan profil komoditi dari perusahaan yang pernah melewati penetapan jalur ini akan dijadikan acuan untuk menentukan profil dari sebuah perusahaan.

Maulidi (2017: 1) menyatakan bahwa, dwelling time adalah lamanya waktu seluruh proses mulai dari bongkar muat barang hingga barang keluar dari pelabuhan. Waktu berapa lama peti kemas (barang impor) ditimbun di Tempat Penimbunan Sementara (TPS) di pelabuhan sejak dibongkar dari kapal sampai dengan barang impor keluar dari TPS. Sedangkan menurut Yulianto (2016: 1) yaitu dwelling time merupakan sebuah proses yang dibutuhkan sejak barang/peti kemas turun dari kapal/pesawat atau barang/peti kemas ditumpuk di lapangan penumpukan hingga barang/peti kemas keluar dari terminal pelabuhan/bandara.

Bila dianalogikan, dwelling time adalah waktu tempuh. Artinya perjalanan barang impor dari bongkar hingga ke luar pelabuhan/bandara dinyatakan dalam satuan waktu, detik, menit, jam, hari dan seterusnya. Agar dapat diketahui apakah dwelling time bermasalah atau tidak, maka dibutuhkan "angka normal" sebagai acuan.

Secara hitungan, dwelling time merupakan selisih antara waktu saat kontainer dikeluarkan dari pelabuhan/bandara dengan waktu kontainer dibongkar dari sarana pengangkut. Pada rentang waktu sejak barang impor dibongkar hingga barang impor tersebut dikeluarkan dari pelabuhan/bandara, melalui tiga proses (pre, custom dan post) sangat menentukan besaran dwelling time.

Semakin lama barang menumpuk di pelabuhan/bandara, semakin besar biaya yang ditanggung pelaku usaha. Dampaknya, harga jual barang akhir menjadi lebih mahal. Kinerja layanan bongkar muat di pelabuhan/bandara ditentukan banyak unit kerja. Seperti Bea Cukai, Karantina dan operasional swasta di pelabuhan/bandara. Semuanya secara bersama-sama berkongsi mempengaruhi kecepatan layanan pelabuhan/bandara. Setiap unit kerja ini bertanggung jawab terhadap instansinya masing-masing, yang biasanya memiliki pendataan dan model pengukuran berbeda.

Menurut Maulidi (2017: 1), terdapat tiga tahap proses dwelling time yaitu:

1. Pre customs clearance

Tahap sebelum, saat, dan sesudah pemberitahuan kedatangan sarana pengangkut laut / udara, penyerahan manifest yang dilakukan oleh agen pelayaran / penerbangan, kemudian dilanjutkan dengan penyampaian pemberitahuan impor ke Bea dan Cukai.

2. Customs clearance

Tahap pemeriksaan yang terdiri dari pemeriksaan semua dokumen yang telah selesai dan pemeriksaan fisik barang kemudian terhadap barang tersebut dikeluarkan dari tempat penimbunan dan diterbitkan Surat Persetujuan Pengeluaran Barang (SPPB) oleh Bea dan Cukai.

3. Post customs clearance

Tahap setelah Surat Persetujuan Pengeluaran Barang (SPPB) diterbitkan oleh Bea dan Cukai sampai dengan proses pengeluaran barang dari Tempat Penimbunan Sementara (TPS). Di dalam ketiga proses

Tony Triyulianto, et.al (Efektifitas Prosedur Kepabeanan Terkait Dengan Dwelling Time...) 
tersebut, terdapat pemeriksaan karantina yang bila terkait barang berbahaya, memerlukan pemeriksaan laboratorium, sehingga bisa menambah dwelling time.

\section{Efektifitas Prosedur Kepabeanan Terkait Dengan Dwelling Time Untuk Importasi Di Kantor Pelayanan Utama Bea dan Cukai Tipe C Soekarno Hatta Tahun 2017}

Kegiatan importasi diartikan sebagai kegiatan memasukkan barang dari suatu negara (luar negeri) ke dalam wilayah pabean negara lain ( Susilo, 2008:101 ). Dalam kegiatan importasi tersebut, terdapat transaksi impor antara kedua belah pihak. Komoditi yang ditransaksikan dan diimpor ke dalam daerah pabean terutang Bea Masuk dan Pajak Dalam Rangka Impor (PDRI).

Prinsip yang dianut dalam pembayaran bea masuk adalah asas perhitungan sendiri atau self assessment. Sistem self assessment yang diterapkan dalam kepabenan Indonesia yaitu pengguna jasa mengisi dan memberitahukan impor pada formulir Pemberitahuan Impor Barang (PIB) untuk diserahkan kepada Kantor Pelayanan Bea dan Cukai tempat terjadi kegiatan impornya. Pelaksanaan self assessment ini bertujuan untuk mempermudah importir dalam mengurus barang-barangnya, menyederhanakan prosedur penelitian administrasi, dan kelancaran arus barang. Pemberitahuan ini menggunakan sistem self assessment yang memandang wajib pajak sebagai badan yang mampu bertanggung jawab secara hukum. Sistem self assessment yaitu menghitung, melaporkan dan membayar sendiri Bea Masuk yang terutang dalam SPT Pemberitahuan Pabean ( Pemberitahuan Impor Barang/PIB ).

Secara umum, syarat penyerahan barang yang digunakan adalah Cost, Insurance, Freight (CIF) dimana dokumen-dokumen impor yang harus dilengkapi tergantung dari syarat penyerahan barang tersebut. Dalam hal Pemberitahuan pabean, akan disampaikan dalam bentuk pengiriman data melalui media elektronik yang dikenal sekarang dengan sistem EDI (Electronic Data Interchange) ke Kantor Pelayanan Bea dan Cukai. Dengan memakai prinsip self assessment dalam pajak, yaitu menilai, menghitung, menaksir sendiri pemenuhan kewajiban perpajakannya (Nurmantu, 2005, p. 108). Dalam hal kepabeanan, prinsip self assessment ini dilakukan oleh orang/pihak yang melakukan kegiatan kepabeanan, untuk secara jujur memberitahukan jumlah, jenis barang, dan besarnya nilai pabean serta klasifikasi barang untuk perhitungan bea masuk dan pajak dalam rangka impor yang harus dibayar atau dikenal dengan nama importir. ( Purwito, 2006, p. 25 ).

Sesuai dengan wawancara Kepala Seksi Kepabeanan dan Cukai mengenai prosedur kepabeanan. Prosedur kepabeanan dalam importasi barang sudah dimulai saat pihak Bea dan Cukai mendapatkan informasi RKSP (Rencana Kedatangan Sarana Pengangkut) sebelum barang datang ke kantor bea dan cukai. Saat barang impor tiba, pihak pengangkut menyerahkan inward manifest sebelum melakukan pembongkaran barang. Inward manifest yang telah diterima dan mendapat nomor pendaftaran di kantor bea dan cukai merupakan pemberitahuan pabean BC 1.1 dan berlaku sebagai persetujuan pembongkaran barang. Kepala Kantor Bea dan Cukai atau pejabat yang ditunjuknya bisa membatalkan apabila terdapat larangan pemasukan barang impor dari instansi terkait.

Setelah itu, importir/pengguna jasa menyampaikan PIB (Pemberitahuan Impor Barang) ke kantor bea dan cukai. Sebelum membuat PIB, Bea dan Cukai melakukan pemeriksaan dokumen impor terkait dengan adanya barang Lartas (Larangan dan Pembatasan). Pihak importir atau pengguna jasa mentransfer data impornya melalui portal INSW (Indonesia National Single Window) untuk kemudian dicek oleh bagian pejabat yang menangani penelitian barang Larangan dan Pembatasan. Apabila pemenuhan perijinan sudah dipenuhi, PIB dapat dilayani lebih lanjut. Apabila masih kurang perijinannya, otomatis akan dikembalikan ke pihak importir.

Prosedur impor barang dalam penyampaian PIB yang harus dilakukan oleh pihak importir adalah untuk setiap barang impor sebelum dapat diterima oleh pihak yang mengimpor, semua pajak dalam rangka impor harus dilunasi terlebih dahulu. Pajak-pajak yang dikenakan sehubungan dengan impor barang adalah Bea Masuk, Pajak Pertambahan Nilai, Pajak Penghasilan Pasal 22. Mengajukan PIB yang meliputi: kelengkapan uraian jenis barang, tarif dan pembebanan berdasarkan BTKI, harga barang, menghitung bea masuk dan pajak dalam rangka bea impor, kelengkapan dokumen impor, membayar bea masuk dan pajak dalam rangka impor di Bank Devisa Persepsi, mengajukan pemberitahuan impor yang dilengkapi dengan dokumen.

Pihak importir kemudian melakukan penyampaian PIB ke kantor bea dan cukai. PIB yang ditransfer tersebut akan masuk ke sistem bea cukai untuk mendapatkan respon penjaluran. Terhadap jalur hijau dan

Tony Triyulianto, et.al (Efektifitas Prosedur Kepabeanan Terkait Dengan Dwelling Time...) 
prioritas, akan langsung mendapat respon SPPB (Surat Persetujuan Pengeluaran Barang). Sementara terhadap jalur kuning muncul Surat Persetujuan Jalur Kuning (SPJK) dan merah berupa respon Surat Pemberitahuan Jalur Merah (SPJM). Setelah mendapatkan jalur sesuai sistem, pihak importir/pengguna jasa harus menyerahkan PIB beserta dokumen pelengkap pabeannya dan bukti pelunasan bea masuk, cukai dan PDRI nya.

Pihak importir telah diberikan kepercayaan untuk melakukan self assessment dalam pemenuhan kewajiban pabean atas barang yang akan diimpor ke dalam daerah pabean. Dalam pemenuhan kewajiban pabean yang dilakukan importir tetap harus ada kewenangan dalam prosedur kepabeanan untuk menguji kepatuhan importir dengan melakukan pemeriksaan dokumen PIB dengan meneliti kembali kebenaran dan kejelasan pengisian atau laporan yang disampaikan importir yang berdasarkan self assessment.

Pejabat Bea dan Cukai melalui sistem official assessment yaitu suatu sistem pungutan pajak yang memberi wewenang kepada fiskus yaitu Pejabat Bea dan Cukai untuk menentukan besarnya pajak yang terutang dan menempatkan kedudukan wajib pajak yaitu pihak importir dalam sisi pasif dan penghitungan besarnya pajak atau kurang bayarnya bea masuk yang ditetapkan Pejabat Fungsional Pemeriksa Dokumen (PFPD) yang sesuai dengan Pasal 16 UU Kepabeanan. Oleh karena hal tersebut, apabila ada kekurangan pembayaran BM dan PDRI pada jalur hijau, akan muncul respon SPTNP untuk dibayar kekurangannya. Sedangkan untuk jalur kuning, respon SPTNP akan muncul dan harus dibayar sebelum diterbitkan SPPB. Apabila terhadap dokumen PIB jalur kuning tersebut tidak ada kekurangan pembayaran pajaknya, bisa diterbitkan SPPB.

Gambar III.1 Respon dokumen jalur hijau yang terkena SPTNP

\begin{tabular}{|c|c|c|c|c|c|}
\hline lebinim & lilecipian & fism & twa $8 a 2$ & & \\
\hline 428297825 & 1810:70222 & Sems Speguspris? & E & Cali & kin \\
\hline $14 \% 21706008$ & $14+24709: 428$ & 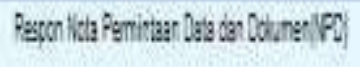 & E & Caki & Kin \\
\hline $31432171+22: 19$ & 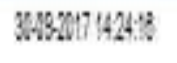 & PexonSPPE & E & Casi & Kinn \\
\hline 240207711800 & 2NB217178:5 & Pescon Biling & E & Calar & Kin \\
\hline 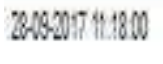 & $2002017711: 54$ & Pasm Pageinan PG & E & (atis) & Kin \\
\hline
\end{tabular}

Sumber : KPUBC Tipe C Soekarno Hatta

Berdasarkan gambar di atas, dokumen jalur hijau oleh importir PT. AA ditransfer tanggal 28 September 2017 dan mendapat respon SPPB tanggal 30 September 2017. Kemudian pada tanggal 14 Oktober 2017, PFPD mengirim NPD (Nota Permintaan Dokumen) untuk dilakukan pengecekan hardcopy dokumen hijau tersebut.

Setelah itu, tanggal 18 Oktober 2017, PFPD mengirim respon SPTNP ke pengguna jasa sebagai tanda ada kekurangan pembayaran bea masuk dan PDRI. 


\begin{tabular}{|c|c|c|c|c|c|}
\hline let Kin & What Patn & Asp: & 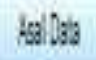 & & \\
\hline 14:2074:4207? & 14:247145:2 & Psesu 958 & : & (a) & $\mathrm{kin}$ \\
\hline 2102798414 & 0812078112 & 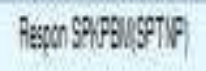 & $\vdots$ & $8 \mathrm{~B}$ & (inin \\
\hline 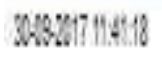 & 31.WWT71:B8 & Pesun SPK & $\vdots$ & $\mathrm{Cat}$ & $\operatorname{rim}$ \\
\hline 2NR2T:384 & 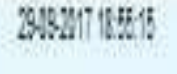 & Pesco Bling & $\vdots$ & $\mathrm{Cg}$ & $\mathrm{rim}$ \\
\hline $2 \times 1077488$ & 24821716344 & Pesu Perentupes & $\vdots$ & $\cos$ & Kin \\
\hline
\end{tabular}

\section{Gambar III.2 Respon dokumen jalur kuning yang terkena SPTNP}

Sumber :KPUBC Tipe C Soekarno Hatta

Berdasarkan gambar di atas, PT. BB mendapatkan respon jalur kuning dilihat dari respon SPJK pada tanggal 30 September 2017, kemudian setelah dokumen jalur kuning dimasukkan ke pendok PIB dan didistribusikan ke PFPD, kemudian muncul respon SPTNP pada tanggal 2 Oktober 2017 Importir tersebut kemudian membayar kekurangan bea masuk dan PDRI-nya tanggal 4 Oktober 2017 sehingga muncul respon SPPB.

Selain pemeriksaan terhadap dokumen PIB, Bea dan Cukai juga melakukan prosedur pemeriksaan fisik barang terhadap PIB yang terkena penjaluran merah. Pemeriksaan terhadap barang jalur merah bukan ditujukan untuk menghambat arus pengeluaran barang, namun sesuai dengan fungsi dan wewenang Pejabat Bea dan Cukai agar dapat meyakini bahwa dalam setiap impor barang ke dalam daerah pabean tidak ada pelanggaran peraturan perundangan yang berlaku yang bisa merugikan atau membahayakan negara.

Pemeriksaan fisik dilakukan oleh Pemeriksa barang impor.Dalam hal ini, pemeriksa melakukan prosedur pemeriksaan dengan didampingi oleh importir/kuasanya yang menyiapkan barang untuk diperiksa fisik. Kemudian pemeriksa membuat Laporan Hasil Pemeriksaan (LHP) yang berisi tentang penjelasan deskripsi barang-barang impor yang diperiksa oleh pemeriksa barang. LHP tersebut diserahkan pemeriksa barang ke PFPD untuk dilakukan penelitian lebih lanjut terkait klasifikasi barang ataupun nilai pabean yang dilaporkan importir. Dalam hal PFPD yang mempunyai wewenang official assessment dalam penghitungan pajaknya, PFPD juga memakai LHP sebagai filter untuk menerbitkan respon SPPB.

\section{Gambar III.3 Alur proses impor barang yang terkena jalur merah}

\begin{tabular}{|c|c|}
\hline URAIAN STATUS & WAKTU STATUS \\
\hline Waktu Dinystakan Sigp Pemeriksan Barang & 10.10-2017 14:58:57 \\
\hline Waktu Selessi Periksa Fisik oleh PFPB & $10-10-201718: 00: 00$ \\
\hline Waitu selesai pengisisn LHP & $11-10-201714: 04: 30$ \\
\hline Waktu mulsi pengisian LHP & $11 \cdot 10 \cdot 201714: 00: 10$ \\
\hline Waktu Mulai Periksa Fisik oleh PFPB & 10-10-2017 15:30:00 \\
\hline Waktu data dismbil PFPD Merah / Hijgu & $12 \cdot 10 \cdot 201715: 10: 19$ \\
\hline Waltu SPPB & $12 \cdot 10-201718: 39: 30$ \\
\hline Waktu PIB selessi diperiks PFPD Merah / Hijau & $12 \cdot 10 \cdot 201718: 39: 31$ \\
\hline Wastu keluar dari gate & $14 \cdot 10 \cdot 201710: 09: 09$ \\
\hline $144 \sqrt{2} / 2+1$ & {$[11-19 / 19]$} \\
\hline
\end{tabular}




\begin{tabular}{|c|c|}
\hline URAIAN STATUS & WAKTU STATUS \\
\hline Waktu Data Diterima di KPBC & 29-09-2017 13:48:33 \\
\hline Waktu Selesai Insert ke TIT. Siap Divalidasi & 29-09-2017 13:48:33 \\
\hline Waktu Selesai di-Validasi & 29-09-2017 13:48:38 \\
\hline Waktu terseleksi sbg Payment Verification & 29-09-2017 13:49:15 \\
\hline Waktu selessi terseleksi sbg Payment Verification & 29-09-2017 18:39:01 \\
\hline Waktu Siap dilakukannya Penjaluran & 29-09-2017 18:39:01 \\
\hline Waktu Jalur Merah / Hijau & 29-09-2017 18:39:25 \\
\hline Waktu SPJM & 29-09-2017 18:39:25 \\
\hline Waktu diterima Berkas PIB dan Lampiran & 02-10-2017 08:52:02 \\
\hline Waktu Penunjukkan PFPB Sesuai SE-06/2007 & 10-10-2017 14:58:57 \\
\hline $14+1 / 2 *+1$ & {$[1-10 / 19]$} \\
\hline
\end{tabular}

\section{Sumber : KPUBC Tipe C Soekarno Hatta}

Berdasarkan gambar di atas, PT CC mendapatkan jalur merah dalam proses importasinya. Respon saat mendapat jalur merah yaitu saat respon SPJM pada tanggal 29 September 2017. Kemudian dokumen diterima bea dan cukai tanggal 2 Oktober 2017 dan waktu penunjukan pemeriksa fisik barang tanggal 10 Oktober 2017. Proses penunjukan sangat lama bisa disebabkan kesiapan dari pengguna jasa untuk memeriksa barang juga lama. Pemeriksaan fisik selesai hari itu juga pukul 16.00 WIB tetapi pembuatan LHP baru keesokan harinya tanggal 11 Oktober 2017 dan baru diterima PFPD tanggal 12 Oktober 2017 sehingga pemutusan SPPB juga baru hari itu.

Setelah muncul respon SPPB, prosedur kepabeanan yang terakhir adalah persetujuan pengeluaran barang dari gudang impor. Bea dan Cukai yang bertugas sebagai petugas pintu pengeluaran barang harus memastikan dokumen PIB hardcopy dan PIB di system terhadap barang yang akan dikeluarkan dari gudang impor sama. Apabila ada perbedaan dalam hal nomor master Airwaybill, berat dan dimensi maupun jumlah koli harus dilakukan pembetulan PIB dengan persetujuan Kepala Seksi kepabeanan dan cukai. Apabila tidak ada perbedaan, akan diberikan persetujuan keluar untuk proses pengeluaran barang.

Dalam hal pengeluaran barang, importir atau pengusaha jasa kepabeanan tidak langsung mengeluarkannya setelah mendapat paraf dan respon persetujuan pengeluaran barang tersebut. Hal- hal seperti belum sampainya transportasi yang mengangkut barang tersebut, barang di gudang impor yang masih ada stock dan belum waktu produksi, maupun biaya sewa yang lebih mahal di luar gudang impor membuat importir menimbun lebih lama lagi di gudang. Hal tersebut harus menjadi perhatian serius sehingga tidak menambah penuh barang impor yang seharusnya sudah keluar dari gudang.

Secara garis besar, prosedur kepabeanan tersebut dapat digambarkan melalui alur rangkaian yang sistematis yang dapat memudahkan dalam pemahaman terhadap konsep prosedur kepabeanan tersebut. Berikut ini merupakan suatu bentuk flowchart dari rangkaian prosedur kepabeanan di Kantor Pelayanan Utama Bea dan Cukai Tipe C Soekarno Hatta.

Gambar III.4 Flowchart prosedur kepabeanan secara keseluruhan:

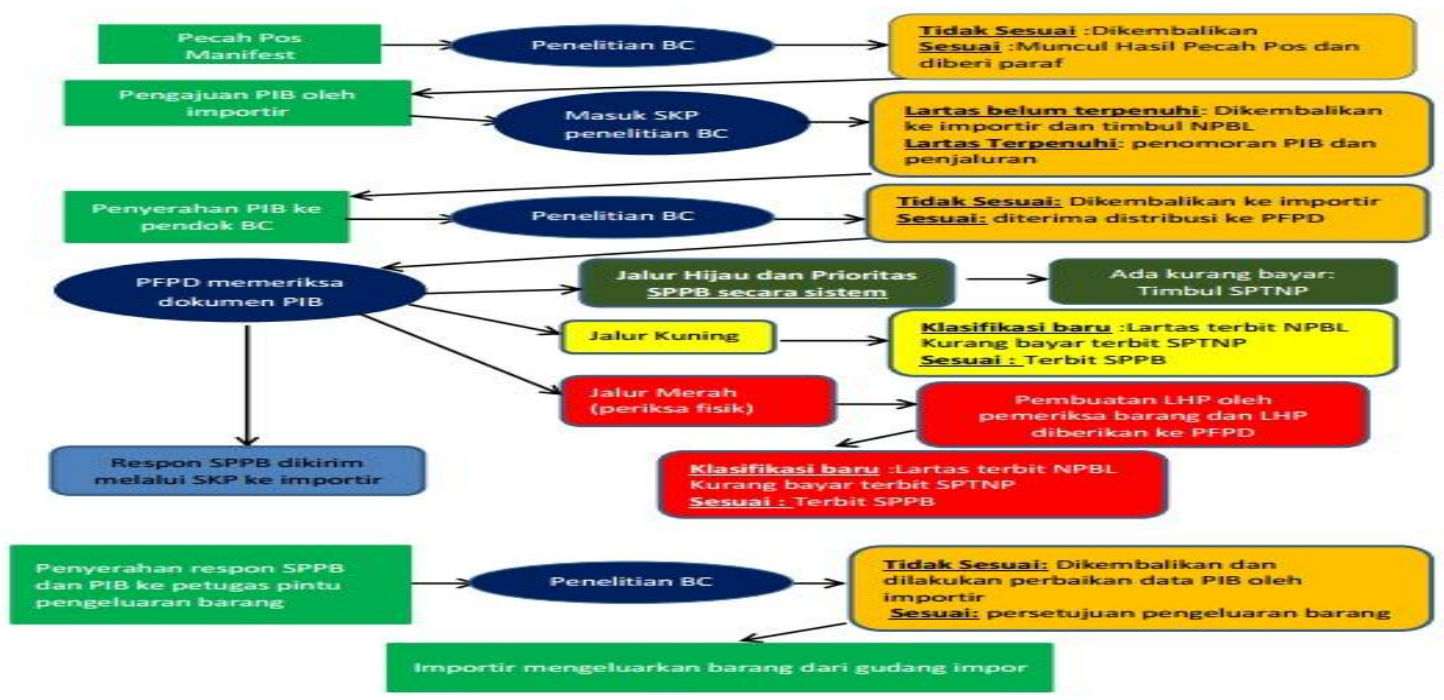

Tony Triyulianto, et.al (Efektifitas Prosedur Kepabeanan Terkait Dengan Dwelling Time...) 
Penjelasan prosedur kepabeanan di KPUBC Tipe C Soekarno Hatta sebagai berikut:

1. Pelayanan Manifest (Pecah Bos / BC 1.1) Waktu layanan : 10-15 menit

a. Pemohon mengajukan permohonan pecah pos

b. Pelaksana seksi manifest meneliti

Sesuai : pemecahan pos dan menginputnya di sistem kemudian melakukan paraf

Tidak sesuai : dikembalikan ke pemohon

2. Pelayanan Penelitian Barang Larangan dan Pembatasan Waktu layanan : Paling lama 3 hari kerja

a. SKP (Sistem Komputer Pelayanan) menerima data PIB dan melakukan penelitian status importir/PPJK serta kelengkapan data PIB dan kode billing

b. Importir melakukan pembayaran sesuai data billing / menyerahkan jaminan

c. SKP/petugas Analyzing Point (penindakan) melakukan penelitian terkait lartasnya

Ada lartas: ada penerbitan NPBL (Nota pemberitahuan Barang Lartas) dan importir harus melengkapinya

Tidak ada lartas: Muncul nomor pendaftaran PIB untuk mendapat penjaluran PIB

3. Pelayanan Penerimaan Dokumen PIB (semua jalur) Waktu layanan : 5 menit

a. Pengguna jasa mengambil antrian dan menunggu panggilan nomor antriannya

b. Petugas Pendok memanggil nomor antrian dan pengguna jasa yang dipanggil segera menyerahkan dokumennya

c. Penelitian oleh petugas pendok

Lengkap: dokumen diterima dan petugas membuatkan tanda terima untuk pengguna jasa

Tidak lengkap: dokumen ditolak dan dikembalikan ke pengguna jasa untuk dilengkapi terlebih dahulu

4. Pemeriksaan Dokumen PIB oleh PFPD (persetujuan SPPB) Jalur prioritas dan hijau sudah langsung SPPB secara sistem Jalur kuning maksimal 2,5 hari dari dokumen diterima

Jalur merah maksimal 2,5 hari dari dokumen dan LHP dari pemeriksa barang diterima

a. Jalur Prioritas : Langsung SPPB

b. Jalur Hijau : Langsung SPPB

c. Jalur Kuning

1) PFPD memeriksa dokumen jalur kuning yang sudah diterima dari petugas pendok

2) PFPD melakukan penelitian klasifikasi barang Pos

Tarif sesuai : dilanjutkan penelitian tarif

Tidak sesuai : PFPD mengubahnya ke klasifikasi barang yang seharusnya

Apabila klasifikasi barang mengacu ke lartas, diterbitkan NPBL (Nota Pemberitahuan Barang Lartas)

3) PFPD melakukan penelitian tarif barang

Tarif sesuai : dilanjutkan ke profil importir

Tidak sesuai : PFPD mengubah ke pos tarif yang seharusnya

4) PFPD melakukan penelitian nilai pabean

Masih wajar : mengikuti nilai pabean yang dilaporkan importir

Tidak wajar : diterbitkan INP (Informasi Nilai Pabean) dan importir wajib menyerahkan DNP maksimal 3 hari dari penerbitan INP

5) PFPD meneliti ulang tarif dan nilai pabean tersebut

Nilainya tidak sesuai dan kurang bayar : diterbitkan SPTNP

Nilainya sesuai : diterbitkan SPPB

d. Jalur Merah

Prinsipnya sama seperti jalur kuning. Perbedaannya ada pada dokumen awal dasar penelitian ditambahkan data LHP (Laporan Hasil Pemeriksaan ) dari pemeriksa barang di gudang. Setelahnya sama sampai diterbitkannya SPPB.

Dwelling time pada tabel I.3 dikaji dari proses ini, dikarenakan sudah ada penetapan jalurnya. Proses pemeriksaan dari jalur-jalur tersebut sampai diterbitkannya SPPB menjadi tolak ukur angka dwelling time yang diteliti pada tabel tersebut.

5. Pemeriksaan Fisik Barang Jalur Merah

Waktu layanan : Tergantung jumlah dan jenis barang Pembuatan dan penyerahan LHP ke PFPD : barang $<100$ item $=60$ menit 
barang $>100$ item $=120$ menit

a. Importir menerima pemberitahuan pemeriksaan fisik kemudian menyiapkan barang yang akan diperiksa dan pemberitahuan ke Kepala Seksi Pabean

b. Kepala Seksi menerbitkan IP(Intruksi Pemeriksaan) dan menyampaikannya ke pemeriksa

c. Pemeriksa menerima IP beserta dokumen pelengkapnya dan menuju ke tempat pemeriksaan

d. Importir membuka kemasan dan pemeriksa melakukan pemeriksaan, melakukan penelitian jumlah dan jenis barang dan menghitung jumlah dan nomor seri di barang

e. Pemeriksa barang melakukan :

- Pemeriksaan fisik dan membubuhkan paraf pada kemasan yang diperiksa dan foto barang serta dokumen pelengkapnya

- Membuat BAP (Berita Acara Pemeriksaan) lalu menandatangani bersama importir

- Membuat kesimpulan pemeriksaan dan menuangkan di LHP (Laporan Hasil Pemeriksaan)

- Melakukan perekaman LHP dan mengirimkan foto barang melalui SKP ke PFPD

f. Apabila ada contoh barang, segera diserahkan ke bagian PFPD sebagai acuan dalam memutus dokumen PIB.

6. Pelayanan Persetujuan Pengeluaran

Barang Waktu layanan : 5-10 menit

a. Pengguna jasa menyerahkan dokumen PIB beserta respon SPPB ke petugas bea cukai pintu

b. Petugas Bea cukai pintu melakukan pengecekan jumlah dan berat barang

Tidak sesuai : ditolak dan dilakukan perbaikan data PIB

Sesuai : Diberikan persetujuan pengeluaran barang dan barang dikeluarkan oleh pengguna jasa

Pelaksanaan prosedur kepabeanan terhadap importasi barang membutuhkan waktu tempuh penyelesaian yang disebut dwelling time. Tinggi rendahnya angka dwelling time, akan menjadi acuan efektifitas dari pelaksanaan prosedur kepabeanan. Menurut pendapat Muasaroh (2010:13), akan dijelaskan bahwa efektifitas dari prosedur kepabeanan di KPUBC Tipe C Soekarno Hatta terkait dengan dwelling time dapat dilihat dari aspek-aspek :

a. Aspek tugas atau fungsi

Pada aspek ini lembaga dikatakan efektif jika melaksanakan tugas atau fungsinya, begitu juga suatu program akan dapat berjalan efektif jika tugas dan fungsinya dapat dilaksanakan dengan baik. KPU BC Tipe C Soekarno Hatta mempunyai tugas dan fungsi melayani dan mengawasi arus lalu lintas impor ekspor barang sehingga efektifitas dari proses kepabeanan tersebut dinilai dari apakah prosedur dilaksanakan dengan baik atau tidak. Menurut Kepala Seksi Kepabeanan dan Cukai, Prosedur kepabeanan yang dilakukan bea cukai pada importasi barang masih belum efektif dikarenakan :

- Tugas pegawai Analyzing Point dalam memutus dokumen lartas masih terlampau lama.

- Tugas pegawai penerimaan dokumen PIB dalam pemeriksaan kelengkapan berkas PIB masih agak lama dan pendistribusian dokumen ke PFPD tidak langsung didistribusikan.

- Tugas pemeriksa barang impor dalam pembuatan laporan pemeriksaan fisik kurang cepat didistribusikan ke PFPD.

Secara garis besar, prosedur kepabeanan sudah dilakukan sesuai tugas dan fungsinya. Akan tetapi, terlepas dari pihak pengguna jasa yang masih ada beberapa kekurangan seperti lamanya penyampaian dan penyerahan dokumen PIB ke pihak bea dan cukai ataupun kesiapan untuk pemeriksaan fisik, pihak bea dan cukai juga masih belum efektif dalam pelaksanaan tugas atau fungsinya yang menyebabkan angka dwelling time menjadi lebih tinggi.

b. Aspek rencana atau program

Pada aspek ini, Akan disebut efektif apabila seluruh rencana yang terprogram dapat dilaksanakan dengan baik. Dalam hal mengatasi angka Dwelling time supaya tidak meninggi, KPU BC Tipe C Soekarno Hatta tentu saja mempunyai rencana dalam pelaksanaan prosedur kepabeanan tersebut seperti :

- Pembuatan loket dengan sistem satu pintu dalam pengurusan dokumen impor

Program ini sudah dijalankan sejak April 2017 dengan tujuan untuk memudahkan pengguna jasa dalam pengurusan dokumen impor dengan tidak perlu berlari-lari ke loket satu dan lainnya. Dalam prosesnya, berjalan efektif tetapi para pengguna jasa merasa lebih lama dan kurang efektif dalam proses penyelesaian dokumennya dikarenakan memakai sistem antrian panggilan 
sehingga apabila ada pengguna jasa yang membawa dokumen yang banyak tentu akan membuat antrian selanjutnya menunggu lama.

- Program perbantuan pemeriksa barang impor di gudang yang volume impornya sedang tinggi

Pernah dilakukan pada bulan Juli 2017 dengan tujuan mengurangi angka dwelling time akibat menumpuknya barang impor yang menunggu antrian pemeriksaan fisik. Pada saat itu, volume jalur merah bulan Juli mencapai 1590 dokumen dengan dwelling time mencapai 10,85 hari. Program ini berjalan efektif dikarenakan di bulan Agustus angka dwelling time turun menjadi 7,96 hari padahal dokumen naik menjadi 2287 dokumen.

Program jam lembur kerja untuk petugas pintu di gudang impor yang barangnya menumpuk untuk dikeluarkan Pernah dilakukan pada bulan November 2017. Di saat itu, volume barang jalur prioritas,hijau, kuning, dan merah sedang tinggi-tingginya. Prioritas dengan 7035 dokumen, hijau 19.273 dokumen, kuning 8283 dokumen dan merah 3446 dokumen dimana waktu SPPB yang berbarengan dalam tiap harinya, tentu akan menimbulkan antrian pengeluaran barang. Jam kerja bea cukai di gudang impor dari jam 08.00-16.30 WIB terasa kurang sehingga ada penambahan jam kerja selama 2 minggu sampai jam 19.00 WIB untuk membantu persetujuan pengeluaran barang supaya memiliki waktu lebih panjang.

Rencana atau program-program tersebut sudah terlaksana dengan baik sehingga prosedur kepabeanan bisa dikatakan efektif dalam rangka memperkecil angka dwelling time.

c. Aspek ketentuan dan peraturan

Pada aspek ini, prosedur kepabeanan bisa dikatakan efektif apabila sudah dilaksanakan sesuai ketentuan dan peraturan yang dibuat. Berdasarkan wawancara dengan Kepala Seksi Kepabeanan dan cukai, acuan utama dalam pelaksanaan prosedur kepabeanan importasi barang yaitu UU Kepabeanan no 17 tahun 2006 tentang kepabeanan yang diatur lebih rinci pada Peraturan Direktur Jenderal Bea dan Cukai Nomor PER-12/BC/2016 tentang Pemeriksaan Fisik Barang Impor ataupun Peraturan Direktur Jenderal Bea dan Cukai Nomor PER-16/BC/2016 tentang Petunjuk Pelaksanaan Pengeluaran Barang Impor Untuk Dipakai.

- UU No 17 Tahun 2006 tentang Kepabeanan

Pasal 3, Terhadap barang impor dilakukan pemeriksaan pabean yang meliputi penelitian dokumen dan pemeriksaan fisik barang $=$ sudah dilakukan sebagai dasar pengawasan terhadap importasi barang

Pasal 14, Untuk penetapan tarif bea masuk dan bea keluar, barang dikelompokkan berdasarkan sistem klasifikasi barang = dilakukan oleh PFPD dengan sistem official assestment sehingga apabila diketemukan adanya kekurangan pembayaran bea masuk dan Pajak Impornya akan diterbitkan SPTNP oleh PFPD.

- Per-12/BC/2016 tentang Pemeriksaan Fisik Barang Impor Pasal 5, Pemeriksaan Fisik barang impor dilaksanakan berdasarkan manajemen risiko dimana tingkat pemeriksaan $10 \%$ untuk importir dengan tingkat risiko rendah atau $30 \%$ untuk barang impor dari importir tingkat menengah / tinggi = sudah dilakukan dalam gudang impor, dengan ada 30 item dari importir A resiko rendah diperiksa hanya cukup 3-5 item sedangkan importir B resiko tinggi sekitar 10-15 item yang berfungsi untuk menekan angka dwelling time dikarenakan apabila semua importasi barang diperiksa sampai $100 \%$ tentu akan menghabiskan banyak waktu. Hal-hal seperti ini dikecualikan dari importasi barang yang direkomendasikan untuk pemeriksaan $100 \%$.

Pasal 9, Pelaksanaan pemeriksaan fisik dilakukan dengan mendasarkan pada daftar kemasan (packing list) yang telah ditandasahkan oleh petugas penerima dokumen dan dalam hal packing list (PL) tidak disampaikan, pemeriksaan fisik didasarkan pada Pemberitahuan Pabean Impor.

Dalam hal ini, telah disesuaikan dalam pemeriksaan, packing list menjadi acuan sebagai pemeriksaan barang apakah barang impor sesuai dengan PL atau tidak. Apabila tidak ada PL nya, pemeriksa dapat menentukan barang tersebut dengan dasar acuan yang terlampir di lembar lanjutan PIB.

- Per-16/BC/2016 tentang Petunjuk Pelaksanaan Pengeluaran Barang Impor Untuk Dipakai.

Pasal 19, Terkait dengan barang Larangan Pembatasan, barang impor hanya dapat dikeluarkan dari Kawasan pabean atau tempat lain yang diperlakukan sama dengan TPS, setelah persyaratan dari instansi terkait terpenuhi $=$ Sudah dilakukan oleh pihak bea dan cukai oleh bagian pengawasan bahwa terhadap barang yang terkena lartas akan diberi segel pengaman dan tidak bisa dikeluarkan dari kawasan pabean sampai ijin lartasnya dipenuhi terlebih dahulu. 
Pasal 26, Dalam hal impor oleh jalur AEO ataupun Mitra Prioritas ditetapkan jalur merah,barang dapat dikeluarkan dari kawasan pabean untuk dilakukan pemeriksaan fisik di tempat importir = dalam hal ini, dilakukan dengan perutusan surat tugas ke pemeriksa untuk mengunjungi tempat importir ataupun oleh bea cukai CC (Client Coordinator) Mitra dan AEO dalam kunjungan kerja ke tempat importir.

Dengan pelaksanaan prosedur kepabeanan tersebut,maka dalam aspek ketentuan dan peraturan, pelaksanaan prosedur kepabeanan tersebut termasuk kategori efektif.

d. Aspek tujuan atau kondisi ideal

Dalam aspek ini, suatu program kegiatan dikatakan efektif dari sudut hasil jika tujuan atau kondisi ideal program tersebut tercapai. Berdasarkan dengan wawancara terhadap Kepala Seksi Kepabeanan dan cukai, dalam konteks pelaksanaan prosedur kepabeanan terkait dengan dwelling time pada importasi barang,ada suatu tujuan atau kondisi ideal yang diinginkan yaitu dwelling time yang tercapai dalam penyelesaian prosedur kepabeanan impor adalah 1 (satu) hari. Kondisi itu tercermin di kontrak kinerja Kepala KPU Bea dan Cukai Tipe C Soekarno Hatta.

Dalam pelaksanaannya prosedur tersebut, dari keempat jalur yang dilayani, rata-rata yang didapat dari 2 (dua) jalur pelaksanaannya kurang dari 1 (satu) hari dan 2 (dua) jalur lainnya melebihi 1 (satu) hari.

Untuk mengukur nilai efektivitas secara lebih rinci digunakan kriteria berdasarkan Kepmendagri No.690.900.327 tahun 1994. yaitu:

Tabel III.1 : Rasio Efektifitas

\begin{tabular}{|c|c|}
\hline Rasio Efektivitas (\%) & Kriteria \\
\hline$>100 \%$ & Sangat Efektif \\
\hline $90 \%-100 \%$ & Efektif \\
\hline $80 \%-90 \%$ & Cukup Efektif \\
\hline $60 \%-80 \%$ & Kurang Efektif \\
\hline$<60 \%$ & Tidak Efektif \\
\hline
\end{tabular}

Dalam hal ini $100 \%=1$ hari kerja (efektif)

a. Jalur Prioritas $=$ rata-rata 0,00065 hari kerja

$(1 / 0,00065) \times 100 \%=153846,15 \%$ ( > 100\% = sangat efektif $)$

b. Jalur Hijau $=$ rata-rata 0,00086 hari kerja

$(1 / 0,00086) \times 100 \%=116279,07 \%(>100 \%=$ sangat efektif $)$

c. Jalur Kuning $=$ rata-rata 2,76 hari kerja

$(1 / 2,76) \times 100 \%=36,23 \%$ ( tidak efektif)

d. Jalur Merah $=$ rata-rata 6,27 hari kerja

$(1 / 6,27) \times 100 \%=15,95 \%$ (tidak efektif) 
Tabel III.2 Perbandingan jumlah dokumen, rata-rata dwelling time, kondisi ideal yang ingin dicapai

\begin{tabular}{|l|c|c|c|}
\hline Jalur & $\begin{array}{c}\text { Jumlah } \\
\text { dokumen } \\
\text { Tahun 2017 }\end{array}$ & $\begin{array}{c}\text { Rata-rata } \\
\text { Dwelling Time } \\
\text { per bulannya } \\
\text { Tahun 2017 } \\
\text { (dalam hari) }\end{array}$ & $\begin{array}{c}\text { Kondisi Ideal yang } \\
\text { ingin dicapai } \\
\text { (dalam hari) }\end{array}$ \\
\hline Prioritas & 59.837 & 0,00065 & $<1$ (efektif) \\
\hline Hijau & 206.233 & 0,00086 & $<1$ (efektif) \\
\hline Merah & 23.659 & 2,76 & $>1$ (tidak efektif) \\
\hline
\end{tabular}

Sumber : KPUBC Tipe C Soekarno Hatta

Berdasarkan tabel di atas, dengan kondisi seperti itu, maka pelaksanaan prosedur kepabeanan masih belum efektif bila dikaitkan dengan target ataupun kondisi ideal yang ingin dicapai sehingga masih perlu ditingkatkan lagi keefektifan dari prosedur kepabeanan tersebut sehingga bisa mencapai target 1 (satu) hari dari dwelling time yang ingin dicapai.

\section{CONCLUSIONS}

Tingkat efektifitas prosedur kepabeanan terkait dengan dwelling time untuk importasi di Kantor Pelayanan Utama Bea dan Cukai Tipe C Soekarno Hatta dinilai melalui 4 (empat) indikator:

a. Aspek tugas atau fungsi

Belum efektif dilihat dari tugas pegawai Analyzing Point bea cukai, tugas pegawai pendok, tugas pemeriksa barang yang lama dalam pelaksanaan tugas dan fungsinya

b. Aspek rencana atau program

Efektif dilihat dari program loket satu pintu untuk kemudahan pengurusan dokumen impor, penambahan pemeriksa barang impor, program jam lembur untuk memperlancar arus impor barang.

c. Aspek ketentuan dan peraturan

Efektif dilihat dari pelaksanaan prosedur kepabeanan yang dijalankan sesuai UU no 17 tahun 2006 tentang kepabeanan, Perdirjen PER No 12/BC/2016 tentang pemeriksaan fisik barang impor, Perdirjen PER No 16/BC/2016 tentang petunjuk pelaksanaan barang impor untuk dipakai.

d. Aspek tujuan atau kondisi ideal

Efektif apabila mencapai tujuan dwelling time dalam penyelesaian customs clearance yaitu 1 (satu) hari atau di bawah 1 (satu) hari. Dari 4 (empat) jalur yang ada didapati :

- 2 (dua) jalur yaitu jalur prioritas dan jalur hijau sudah efektif karena di bawah 1 (satu) hari

- 2 (dua) jalur lainnya yaitu kuning dan merah belum efektif dikarenakan masih di atas 1 (satu) hari.

\section{REFERENCES}

Keraf, Gorys. 2008. Diksi dan Gaya Bahasa. Jakarta: PT Gramedia Pustaka Utama.

Lestari, Cinta. 2013. Pengertian Analisis. Diakses dari Internet: http://pengertianbahasa.blogspot.co.id, tanggal 12 Maret 2018.

Maulidi, Achmad. 2017. Pengertian Dweling Time di Pelabuhan. Artikel diakses dari Internet: https://www.kanalinfo.web.id, tanggal 12 Maret 2018.

Purwito, Ali. 2013. Kepabeanan Indonesia. Tanggerang Selatan: Jelajah Nusa. 
Susilo, Andi. 2008. Buku Pintar Ekspor-Impor. Jakarta: Trans Media Pustaka.

Yulianto, Agus. 2016. Dweling Time dan Problematikanya. Artikel Diakses dari Internet: http://www.republika.co.id, tanggal 12 Maret 2018.

\section{Dokumen:}

Undang-Undang Nomor 17 Tahun 2006 tentang Perubahan Atas Undang-Undang Nomor 10 Tahun 1995 tentang Kepabeanan.

Undang-Undang Nomor 36 Tahun 2008 tentang Perubahan Keempat Atas Undang-Undang Nomor 7 Tahun 1983 tentang Pajak Penghasilan.

Undang-Undang Nomor 42 Tahun 2009 Tentang PPN dan PPnBM.

Peraturan Direktur Jenderal Bea dan Cukai Nomor PER-12/BC/2016 tentang Pemeriksaan Fisik Barang Impor.

Peraturan Direktur Jenderal Bea dan Cukai Nomor PER-16/BC/2016 tentang Petunjuk Pelaksanaan Pengeluaran Barang Impor Untuk Dipakai.

Peraturan Direktur Jenderal Bea dan Cukai Nomor PER-37/BC/2016 tentang Perubahan Kedua atas Peraturan Direktur Jenderal Bea dan dan Cukai Nomor PER-16/BC/2016 tentang Petunjuk Pelaksanaan Pengeluaran Barang Impor Untuk Dipakai.

Peraturan Direktur Jenderal Bea dan Cukai Nomor PER-07/BC/2017 tentang Perubahan Ketiga atas Peraturan Direktur Jenderal Bea dan Cukai Nomor PER-16/BC/2016 tentang Petunjuk Pelaksanaan Pengeluaran Barang Impor Untuk Dipakai. 